In the cultural production of humanity, the ship is as a recurrent element associated with the description and characterization of madness. On the other hand, the ship as an icon of passage, also appears in many myths usually associated with states of transience or processing. Analyzing various cultural productions in which that element appears, this paper, presupposing the possibility to approximate recurrent elements and concepts in culture, wants to unveil that in addition to the space of madness as a locus of social exclusion and containment, it could be conversely characterized as the locus of possibility of preservation of the otherness and the space of new gestures.

Keywords: Madness, Alterity, Nau, Sebastian Brant, Foucault, Cultural Studies 


\section{Os habitantes da passagem}

Tatiana Fecchio da Cunha GONÇAVES ${ }^{1}$

Na produção cultural da humanidade, a nau se constitui como um elemento recorrentemente associado à descrição e caracterização da loucura. Por outro lado, a nau como um ícone de passagem também se apresenta em diversos mitos geralmente associada a estados de transitoriedade ou de transformação. Analisando diversas produções culturais nas quais o elemento barca aparece, este ensaio, se pautando na possibilidade de aproximação de elementos e conceitos recorrentes da cultura, pretende desvelar que além de ser o espaço da loucura um lócus socialmente designado ao confinamento e exclusão, inversamente caracteriza como possibilidade de preservação da alteridade e de inauguração de novos gestos.

Palavras-Chave: Loucura, Alteridade, Nau, Sebastian Brant, Foucault, Estudos Culturais 
Na produção cultural da humanidade, a barca se constitui como um elemento recorrentemente associado à descrição e caracterização da loucura. Por outro lado, a barca como um ícone de passagem também se apresenta em diversos mitos geralmente associada a estados de transitoriedade ou de transformação.

Este ensaio, revisitando diversas produções culturais nas quais a barca aparece, e se utilizando da possibilidade de análise comparativa dos conceitos que subjazem e estruturam a construção destes elementos, através da conceituação de pathos formel de Aby Warburg², intenciona desvelar como a barca condensa em si a idéia de um lócus de exclusão e ao mesmo tempo de possibilidade à manutenção da alteridade dentro da cultura.

Para tanto algumas produções culturais serão apresentadas - Das Narrenschiff (Stultifera Navis ou Nau dos Loucos) de Sebastian Brant, O Auto da Barca do Inferno de Gil Vicente, Elogio da Loucura de Erasmo de Rotterdan, o mito grego de Caronte e A Terceira Margem do Rio de Guimarães Rosa - e em cada uma delas elementos de contextos de interesse à análise serão discutidos. Por fim se utilizará metaforicamente a obra e vida de Arthur Bispo do Rosário para discutir como este concatena a ambivalência de ser excluído e proferidor - tendo se constituído como um interno do espaço asilar de exclusão social e ao mesmo tempo inaugurador de uma gestualidade parida na possibilidade de alteridade que o confinamento gerou - o que pode ser extrapolado ao se analisar as demais narrativas abordadas.

A figura da barca habitou o imaginário de diversas culturas e populações. Apenas para citar alguns casos, ela esteve presente nas diversas narrativas das Arcas do Dilúvio ${ }^{3}$ e nas barcas da Morte associadas à forma da meia lua ou à ritos cerimoniais $^{4}$.

Durante a Idade Média, diversas obras se referiram ao barco. A barca como Igreja aparece como local tripulado por cléricos que transportavam a salvo sua carga de almas. O poema alegórico de Guillermo de Deguilleville no século XIV chamado El Peregrinaje de la Vida del Hombre traz referências a esta 
imagem, bem como a Nave da Religião que possui elementos simbólicos do crucifixo e das ordens religiosas da época. A Nau dos Príncipes e das Batalhas da Nobreza, a Nau das Damas Virtuosas de Symphorien Champier, a Nau da Saúde e Blauwe Schute de Jacop van Oestvoren e Stultiferae naviculae scaphae fatuarum mulierum de Josse Bade.

O poema satírico Das Narrenschiff (Stultifera Navis ou Nau dos Loucos) escrito por Sebastian Brant (1457-1521) e publicado pela primeira vez em 1494 trazia como elemento central de sua narrativa uma nau. Este texto, que discorria sobre os vícios humanos 5 , se inseriu num significativo movimento de representações fantasiosas acerca dos estados de tentação e de loucura.
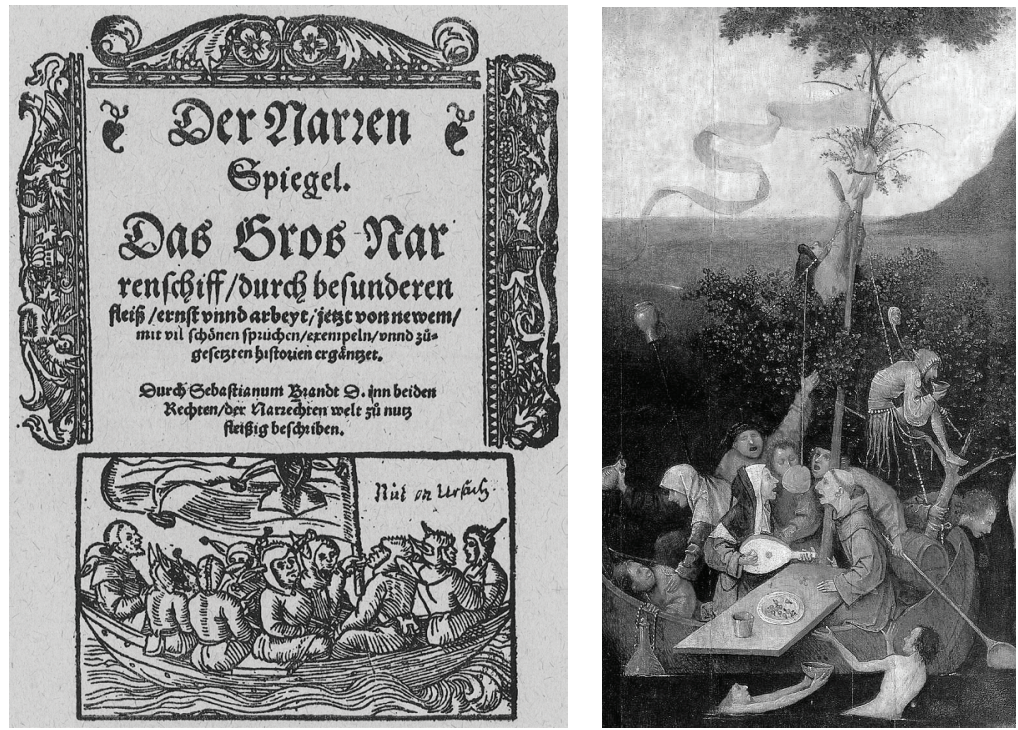

Figura 1 - Página de apresentação da edição de 1549 de Das Narrenschiff de Sebastian Brandt publicada por Wendelin Rihel em Estrasburgo. ${ }^{6}$

Figura 2 - Jheronimus Bosch. The Ship of Fools, 1490-1510 Technique Óleo sobre tabla. Dimensões : $58 \times 33 \mathrm{~cm}$. Museu do Louvre, Paris. ${ }^{7}$

O livro teve por ilustrações, da edição de 1549, xilogravuras de Albrecht Dürer (Figura 1). Deu origem a obras como 
a realizada por Jheronimus Bosch (Figura 2). Estas Naus são abarrotadas, cheias de pessoas que se apertam entre si num espaço reduzido. Os navegantes desta embarcação personificam os diversos vícios ou loucuras na sociedade da época; como o juiz corrupto, o bêbado ou o médico não formado. São alegorias iconograficamente descritas junto a objetos que explicitam seus vícios - como uma garrafa, os gestos exagerados e inadequados.

Uma das figuras presentes na representação de Bosch chama especialmente a atenção por remontar à iconografia da representação da loucura aderida à natureza e à compreensão desta como resultado das más escolhas realizadas no decorrer da vida - representada pela árvore seca de galhada ramificada. A presença de gorros pontiagudos com guizos nas pontas elemento utilizado durante a Idade Média para a identificação dos loucos da corte $^{8}$ - acessa outra tradição de representação referente à figura do bobo. Potencialmente ambivalente, ele se caracteriza como aquele que diz tudo por poder dizê-lo ironicamente, que profere dentro da desqualificação que the cabe.

O limbo social no qual a fala do louco, como bobo, ocorre; contém a possibilidade de dizer por que, a princípio, sua fala pode simplesmente ser desconsiderada. O local de fala do louco fica desta forma aderido a toda a verdade não mediada pela convenção dos padrões sociais; mas, por outro lado, impotente no seu alcance pois proferida por alguém que está fora do circulo de sujeitos considerados naquele sistema.

Esta mesma caracterização ao bobo, aparece na peça $O$ Auto da Barca do Inferno ${ }^{9}$, uma alegoria dramática do escritor português Gil Vicente e que foi representada pela primeira vez em 1517. Ela é a primeira parte da chamada trilogia das Barcas (sendo que a segunda e a terceira são respectivamente o Auto da Barca do Purgatrio e o Auto da Barca da Glria) e traz a imagem de dois barcos dentro de um contexto de crítica social, moralizante ou, no limite, dentro do um contexto de farsa.

Embora não estejam presentes personagens ou tipos sociais que caminham ao mundo da loucura, como na Nau dos Loucos de Brant, as almas das personagens, aqui apresentadas, encontram-se em julgamento num cais que é uma espécie 
de purgatório. Há para elas a possibilidade de seguirem com o Diabo na Barca do Inferno ou com o Anjo na Barca da Glória. Estas barcas são veículos de transporte, elementos que conduzem aos seus destinos as almas no outro mundo, ou a outra ordem.

O personagem Joane, dentre todos os apresentados para julgamento - Fidalgo, Onzeneiro, Sapateiro, Frade com a sua dama, Alcoviteira, Judeu, Corregedor e Cavaleiros - é caracterizado como o tolo, o bobo, uma figura simples e humilde, e que havia pecado não intencionalmente, mas por desconhcimento da norma. Sua culpa não é como a dos demais, que intencionalmente tentam transgredir, mas um resultado inconsequente da sua inocência. A caracterização deste sujeito se dá como alguém que não tem consciência de seus atos, que não faz por mal, que é puro; da mesma forma com a qual também se dava o reconhecimento das falas dos bobos na corte. O Parvo fica, praticamente durante toda a trama, no cais; fazendo comentários acerca das demais personagens, interagindo com todos e auxiliando o Anjo a julgar. Como uma segunda voz de Gil Vicente, Joane fica imiscuido ao julgamento dos barqueiros, proferindo, com a liberdade permitida aos bobos, seus comentários tolos e sábios.

Retornando ao texto de Brandt e à análise da barca, é possível entender esta como um lócus do diverso e do amoral, um mesmo espaço no qual se aglutinam o desatino e as inadequações. Segundo Foucault ${ }^{10}$ a "[...] loucura e o louco tornam-se personagens maiores em sua ambigüidade: ameaça e irrisão, vertiginoso desatino do mundo e medíocre ridículo dos homens"11. No louco é condensado o estado do ininteligível que garante, por diferenciação, algum parâmetro à normalidade. Sobre esta dinâmica Foucault referiu, em sua obra A Ordem do Discurso, que a "[...] doutrina liga os indivíduos a certos tipos de enunciação e Ihes proíbe, conseqüentemente, todos os outros; mas ela se serve, em contrapartida, de certos tipos de enunciação para ligar indivíduos entre si e diferenciá-los, por isso mesmo, de todos os outros"12.

A obra de Brant - que se tornou um poema muito popular, tendo sido traduzido para diversos idiomas ${ }^{13}$ - está inserida 
num imaginário de época que pode ser também aferido por outras produções culturais do período, como na sátira Elogio da Loucura $^{14}$ de Erasmo de Rotterdan (1466-1536). Publicada em 1509, a própria Loucura, como narradora, relata sobre a loucura, objeto do ensaio; numa digressão sobre as diversas formas com as quais estados de sabedoria e criatividade ou de desrazão e amoralidade (inclusive relativos a parâmetros e preceitos teológicos) podem se associar neste conceito.

A nau passa a ser um elemento privilegiado na descrição da loucura, se caracteriza como um local à parte, à margem das margens, lócus do diverso, de purificação (segundo Foucault a água "[...] leva embora, mas faz mais do que isto, purifica"15), de confinamento e exclusão. Mas uma embarcação destinada aos desvarios não foi apenas um elemento alegórico deste período; embora já existissem locais de abrigo a esta população, ela realmente existiu, particularmente em Nuremberg e em Frankfurt. Talvez parte destas naves fosse destinada a viagens de peregrinação e parte realmente a retirar estes sujeitos do convívio social entregando-os à responsabilidade de marinheiros, que se encarregavam de levar os loucos para portos longínquos, garantindo que não voltariam.

A figura da barca aqui se vê acompanhada da figura do marinheiro. Este guia está também presente em alguns textos como no caso de Caronte, na Grécia, que tinha por atribuição transportar os recém-mortos, na sua barca através do rio Aqueronte, até o local do Hades a eles destinado ${ }^{16}$. Fica aferida nesta narrativa a compreensão da experiência após a morte como uma viagem de barco por um rio e a figura do barqueiro, que embora também seja um navegante, se diferencia dos demais por conhecer os caminhos e assim conseguir se deslocar por uma região na qual os demais navegantes não saberiam.

Mas neste conjunto de barca, barqueiro e água (rio); o navegar passa a conter inúmeras significações quando analisado em sua relação com a questão do espaço à loucura. Contendo o navegar o lugar de destino e o tempo de estar desta loucura, o movimento neste decorrer é onde a loucura permanece, ou deveria permanecer, pois a princípio é nenhum país/margem seu definitivo atracar. Neste sentido Foucault comenta que 
"[...] a navegação entrega o homem à incerteza da sorte: nela cada um é confiado a seu próprio destino, todo o embarque é, potencialmente, o último. É para o outro mundo que parte o louco em sua barca louca; é do outro mundo que ele chega quando desembarca ${ }^{17}$. Segundo Foucault esta barca que navega, em certo sentido,

[...] não faz mais do que desenvolver, ao longo de uma geografia semi-real, semi-imaginária, a situação liminar do louco no horizonte das preocupações do homem medieval...; se ele não pode e não deve ter outra priso que o próprio limiar, seguram-no no lugar da passagem. Ele é colocado no interior do exterior, e inversamente. ${ }^{18}$

Neste sentido o louco, navegando e navegado por seu barqueiro, é "[...] o passageiro por excelência, isto é, o prisioneiro da passagem" 19 .

Imediato recordar do conto A Terceira Margem do Rio publicado em 1962 por Guimarães Rosa. Embora dentro de outro contexto de produção, este conto nos re-apresenta elementos semelhantes: um homem que se posiciona em um lócus diverso do ambiente normatizado da sociedade e que ali permanece, em meio ao rio, numa terceira e inusitada nova margem.

Diversas são as passagens que referem ao comportamento do pai como incompreendido, vergonhoso, doido ou inusitado. Em uma delas, o filho, narrador deste conto, sobre o fato de ter o pai decidido morar numa embarcação, comenta:

Nossa mãe, vergonhosa, se portou com muita cordura; por isso, todos pensaram de nosso pai a razão em que não queriam falar: doideira. Só uns achavam no entanto de poder também ser pagamento de promessa; ou que, nosso pai, quem sabe, por escrúpulo de estar com alguma feia doença, que seja, a lepra, se desertava para outra sina de existir, perto e longe de sua família dele. ${ }^{20}$

A ação incompreendida em si, é sujeitada a explicações cabíveis e passíveis de compreensão no meio (vinculações em uma ordem maior e religiosa, na promessa, ou ato de preservação dos iguais, na presença de doença severa e contagio- 
sa), mesmo que não coincidentes com as reais motivações do agente. Curioso também notar como a lepra, que aparece aqui como fator para a explicação do afastamento do personagem de seu meio, é a doença junto a qual esteve a loucura, em diversas instituições desde o século XVII, aderida. Em ambos os estados há a necessidade de exclusão do meio e a perspectiva de morte, física ou social, em suas essências.

O texto de Alessandro Daros Vieira, Notas: Der Narrenkahn ou a Canoa dos Loucos - Uma Anlise Literria do Conto A terceira margem do rio de Joo Guimares Rosa, discute entre outros, sobre a caracterização atribuída à figura do pai na fala do narrador, seu filho. Refere que um dos elementos que caracteriza o pai, e que é tido de forma velada pelo grupo como um estado de doideira, é de certo modo a proposição ou inauguração de uma nova maneira de ser que rompe com o que é esperado num certo sistema ou doutrina.

A doutrina $[\ldots]$ tende a difundir-se: e é pela partilha de um só e mesmo conjunto de discursos que indivíduos, tão numerosos quanto se queira imaginar, definem sua pertença recíproca. [...] A doutrina liga os indivíduos a certos tipos de enunciação e lhes proíbe, conseqüentemente, todos os outros; mas ela se serve, em contrapartida, de certos tipos de enunciação para ligar indivíduos entre si e diferenciá-los, por isso mesmo, de todos os outros ${ }^{21}$.

Como consequência desta diferença, o diverso embora estabeleça e possua em si uma práxis, não se estabelece necessariamente em relação ao socialmente compreensível, passando a ser passível de incompreensão. Segundo Vieira, "[...] o discurso ou a práxis do louco é da ordem de uma naturalidade que se submete ao saber específico que the é vinculado e que transmuta este modo de linguagem, não hegemônica, em loucura, excluindo-a socialmente"22.

O narrador, ao final do conto e em relação à proposição inaugurada pelo ato inusitado do genitor, se deparará com a mediocridade de sua própria vida levada fora do rio, evidenciando, mais uma vez, a aproximação entre transgressão, morte e liberdade, como possibilidade de transcendência e rompimento de limites 
Sou homem, depois desse falimento? Sou o que não foi, o que vai ficar calado. Sei que agora é tarde, e temo abreviar com a vida, nos rasos do mundo. Mas então, ao menos, que, no artigo da morte, peguem em mim, e me depositem também numa canoinha de nada, nessa água que não pára, de longas beiras: e, eu, rio abaixo, rio a fora, rio a dentro - o rio ${ }^{23}$.

Vieira aponta que o falimento do não substituir o pai na embarcação, mas ao mesmo tempo aclamar seu mesmo silêncio de palavras, poderia evidenciar a possibilidade ou desejo de manutenção do estado de alteridade sem rompimento com o contexto social. No entanto, a percepção do rio de longas beiras como lugar possível e da canoinha de nada como espaço habitável, já se constitui por si a inauguração de uma possibilidade inovadora.

Durante a era clássica se constituiu aos poucos a nova forma de apreensão da loucura. Esta passou de bufa, ou escatológica, a determinada pela razão. O louco descrito como irracional, desprovido de razão, traz na associação à etiologia da palavra latina ratio o conceito de bom uso das faculdades intelectuais, mentais e de juízo. Sobre a ausência de racionalidade como critério de patologia, Foucault questiona duplamente seu desígnio, dizendo que a

[...] bela retidão que conduz o pensamento racional à análise da loucura como doença mental deve ser reinterpretada numa dimensão vertical; e nesse caso verifica-se que sob cada uma de suas formas, ela oculta de maneira mais completa e também mais perigosa essa experiência trágica que tal retidão não conseguiu reduzirir ${ }^{24}$.

Mas a ausência de racionalidade não é único conceito a fundamentar a idéia de loucura e é seguramente diverso daquele empregado na apreensão do louco nos contextos de tratamento. Nestes, em geral, é empregada a idéia de a-normalidade, que derivando do latim normalis, se estabelece em oposição à norma, ao esperado como regular e retificado em relação ao postulado dentro de um determinado grupo.

A intervenção institucional, que ganha força na segunda metade do século XVII, se apoiou no binômio normalidade 
versus patologia passando a ser a loucura sistematicamente internada, como a lepra na Idade Média. Este banimento se constituiu como um mecanismo de segregação social e o internamento do século XVII pôde ter sob a larga caracterização de anormalidade os desocupados, os pobres e os desempregados. Em prol de motivos e razões também econômicas, estes sujeitos improdutivos são sistematicamente aprisionados sob pretexto de garantia da ordem social.

Mas novamente aqui o espaço de confinamento se estabelece dentro da mesma ambivalência. Sobre esta dinâmica Foucault comenta que a "[...] hostilidade que o acolhe se tornará, num novo equívoco, a medida de saneamento que o põe fora do caminho. De fato ele continua a vagar, porém não mais no caminho de uma estranha peregrinação: ele perturba a ordem do espaço social"25. O espaço de exclusão, agora o Hospital, é novamente o espaço do diverso insuportável de ser abarcado em determinado contexto social. O Hospital, como a Barca, é o local da diferença. Se nele se encontram os não aceitos, encontra-se também o lcus da possibilidade. Se esta nau não navega fisicamente, nela habitam, abarrotados, os indesejados e inadequados socialmente que, ali, continuam a navegar.

A obra de Machado de Assis (1839-1908), intitulada O Alienista e publicada em 1882 é uma crítica direta a esta forma de conceber e aprisionar a loucura. Sua obra nos conta sobre as peripécias do doutor Simão Bracamante que constrói, na cidade de Itaguaí, a Casa Verde; local no qual deveriam ser internados os mentecaptos. Ao perceber que havia internado grande parte da população, Bracamante questiona seu método científico de diagnóstico e opta por reverter a situação desinternando a maioria da população confinada e internando os que estavam soltos, passando a tomar por real loucura perfeito juzo das faculdades, que so virtuosos, abnegados, modestos e sem vcios. Nesta fase da narrativa a inversão de ser louco o normal, propõe magistralmente a categoria de patologia à normalidade. Mas ao final da narrativa ocorre ainda maior inversão. A internação do médico como o único efetivamente normal em toda a comunidade e exatamente por este motivo o único efetivamente patológico, coloca o próprio saber médico (personifica- 
do na figura de Bacamante), no ambiente de encarceramento, sujeito a tratamento. No hospital psiquiátrico de Machado de Assis está a ser tratado, ao final, o próprio saber legitimado a proferir sobre a anormalidade.

O barco como lócus do diverso, como em Brant e Roterdan, ou como o lugar da alteridade e de uma nova proposição, como em Guimarães Rosa, ou como o espaço legitimado da anormalidade derivado da institucionalização médica, como em Machado de Assis; pode ser concebido e apresentado (ou representado) como este espaço num tempo de suspensão, de um navegar perpetuado na passagem. O barco, como a própria vida que pode ser um grande navegar em passagem, é um campo porém de circulação potente (pois entre portos distantes) e em si restrito (à área desta embarcação). O guia-marinheiro, um habitante privilegiado desta suspensão.

Bispo do Rosário (1911-1989) foi um passageiro-guia-marinheiro de sua embarcação. Encarcerado, ocupou na barca institucional a função de guia, de mediador entre internadores e internados. Tomando o espaço de confinamento por um lócus de alteridade, fez com que ali se constituísse sua fala a princípio silenciosa.

Sua missão era clara bem como era clara sua desadequação à retidão do pensamento. Com suas obras faria um compêndio, julgaria e promoveria a reconstrução de tudo o que havia na Terra, era um "[...] enviado de Deus, um Cristo, quem sabe, mas antes de tudo um maestro empenhado em dirigir a reconstrução do mundo. Um universo de miniaturas, uma espécie de reedição da existência na terra, conforme seus sentidos" 26 .

Rosário foi internado em 1938 no Hospital Psiquiátrico Pedro II sendo posteriormente transferido para a Colônia Juliano Moreira - instituição carioca da primeira metade do século XX, que abrigava negros, pobres, alcolatras e desviantes, localizada no subúrbio de Jacarepaguá. Diagnosticado como esquizofrnico-paranide frequentou as instituições psiquiátricas cariocas por cinquenta anos, entre períodos de internação e desinternação.

Se execeu e produziu nestes anos e nestes espaços. Compôs um universo formado por navios, estandartes, faixas de 
misses e objetos domésticos. Seu trabalho, inicialmente não compreendido dentro do Hospital, foi permitido em função da ajuda dada pelo interno nas dinâmicas cotidianas asilares. Os objetos realizados eram tampouco valorizados, vindo a público apenas na década de 80 , tendo sido conservados mediante inúmeras negociações por seu comandante.

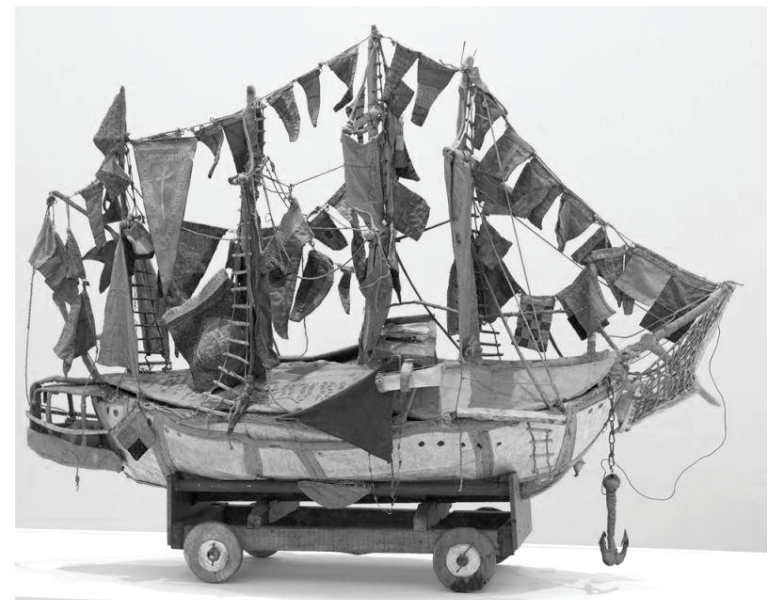

Figura 3 - Bispo do Rosário. Embarcação. Madeira e materiais diversos.

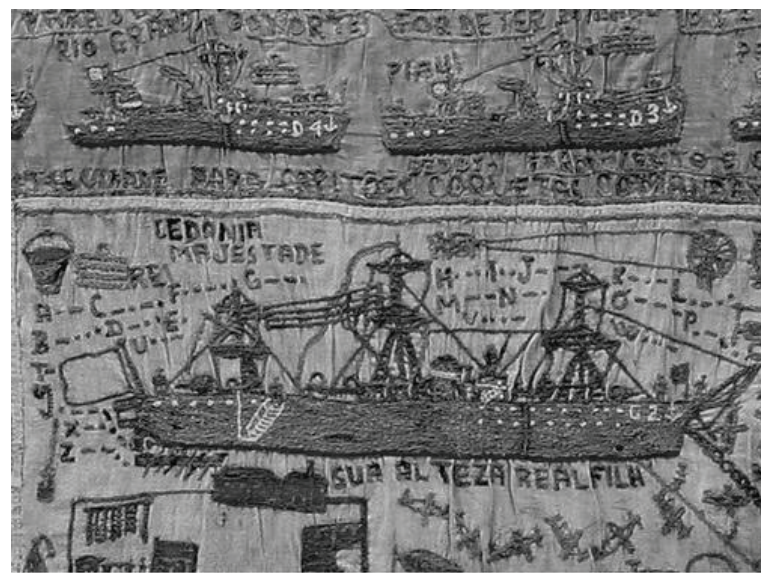

Figura 4 - Bispo do Rosário. Detalhe de estandarte. Tecido e linhas. 
O universo deste sujeito diverso, tomado e retido junto à compreensão social da anormalidade, continha diversas embarcações. O compêndio do mundo que deveria ser realizado, na lógica desta alteridade, trouxe a sua fala elementos de uma história pessoal, transcorrida na juventude como marinheiro ou refletindo sua experiência junto aos navios processionais das festas tradicionais nordestinas.

Presentes desde há muito no nordeste brasileiro, onde também se encontrava a cidade Natal de Rosário, Japaratuba em Sergipe, o barco processional se aproxima de forma múltipla dos elementos encontrados nas embarcações e na poética de Rosário. Na descrição do século XVI feita pelo Padre Fernão Cardim, dentro da narrativa que este fez da festa de Santa rsula e das Onze Mil Virgens na cidade do Salvador diz:

Saiu na procissão uma nau a vela, por terra, mui formosa, toda embandeirada, cheia de estandartes, e dentro dela iam as Onze Mil Virgens ricamente vestidas, celebrando seu triunfo. De algumas janelas falaram a cidade, colégio, e uns anjos todos mui ricamente vestidos. Da nau se dispararam alguns tiros de arcabuzes, e o dia dantes houve danças e outras invenções devotas e curiosas. À tarde se celebrou o martírio dentro da mesma nau, desceu uma nuvem dos Céus, e os mesmos anjos Ihe fizeram um devoto enterramento; a obra foi devota e alegre, concorreu toda a cidade por haver jubileu e pregação. ${ }^{27}$

Coincidentes são as virgens, as estandartes, a nau, os anjos, a pregação. Mas a particularidade mais inusitada é o fato de possuirem as embracações rodas; presença esta justificada nas barcas processionais pois serviam para permitir que estas percorressem as ruas das cidades.

Como uma extenção da função católica divina, ele tece em seu manto os que seguirão, além morte, a boa viagem. O Manto da Apresentao é uma "[...] espécie de mortalha sagrada que bordaria durante toda a vida para vestir no dia da apresentação, no Juízo Final, na data de sua passagem. Bordados neste manto, estariam os nomes das pessoas que ele julgava merecedoras de subir, de carona, rumo ao além" ${ }^{28}$. Neste sentido Rosário seria, ele próprio, o soldado "de uma tropa imaculada, 
reconhecido pelos frades no Mosteiro, ele teria sido enviado para o hospício. De lá julgaria vivos e mortos e regeria o próprio reino" 29 .

O caráter religioso e mágico da experiência de Rosário, por ser designado a assim proceder, não impede que ele se aproxime e se assemelhe daqueles que possuem o discernimento a realização dos julgamentos corretos; selecionar quem seria merecedor da glória no dia do juizo final. Rosário aqui está em função muito semelhante à do Parvo em Gil Vicente, auxilia os julgamentos sendo uma segunda voz do que é da ordem divida: Deus ou, na nossa comparação, o próprio autor - que não deixa de ser o criador/Criador, de qualquer forma.

Frente à Nau dos Loucos é ele próprio, Rosário, seu típico integrante. Diagnosticado e apresentando um pensamento com encadeamentos singulares e inconvencionais, é passível de encarceramento num ambiente reorganizador e moralizador. Mas de dentro do Hospício Rosário rege seu Universo e neste lócus do calar, como opção, ele diz em silêncio determinando uma nova ordem a ser assimilada e compreendida na cultura como possível e passível de perpetuação. Como na figura do pai, na obra de Guimarães Rosa, inaugura com sua ação a possibilidade de uma maneira de corporificar. Habitando a terceira margem/ manicômio/barca, nela constrói sua diferença e singularidade aparentemente excluído mas igualmente contrapondo-se de forma pertinente - e sua obra artística, bem como a repercussão desta no Mundo, é testemunho disto - a padrões preestabelecidos de ser.

Neste contexto também está presente a possibilidade da loucura como aquela que transcende a perspectiva da morte social. Embora excluida e a princípio tomada como encerramento da vida no grupo, esta, em outra ordem, desenvolve sua natureza diversa, possibilitada no desprendimento de uma normalidade inavegante, efetivada no percurso temporário que habita. Como Caronte, Rosário possui todos os dotes para ser um guia, aquele que conduz ao local certo, pois já conhece os caminhos daqueles rios asilares. Sendo bom navegante, se translada a barqueiro integrando elementos de sua vida pré-asilar durante a qual prestou "[...] serviços à Marinha, dos 15 aos 23 anos, na função de 
sinaleiro" 30 .

A passagem se transfigura como lócus de ambivalência, estável e flutuante, e com ela seu morador. O habitante deste suspenso se efetiva no meio e margem, alucinado e discernido, excluído e em diálogo, mudo e proferidor, pecador e puro, normal e anormal, correto e errado, categorizável e inclassificável. A complexidade do humano se evidencia no desejo desesperado de normalidade, se comprova na efetiva qualidade prolixa da existência. A constância da especificidade e da a-normalidade potencializa, no sujeito, a possibilidade de existência na temporalidade e qualidade de navegante.

\section{Notas:}

1. Doutoranda em Artes na Universidade Estadual de Campinas/ Unicamp (FAPESP) tendo realizado estágio sanduíche na Wellcome Trust Centre for the History of Medicine/ UCL Londres (CAPES); Mestre em Artes/ Unicamp (2004); Bacharel e Licenciada em Educação Artística/ Unicamp (2001). Especialista em Arteterapia/ Unicamp (2003) e especialista em Artes e Novas Tecnologias na Universidade de Brasília/ UnB (2005). Membro dos grupos de Pesquisa: Transferência Cultural entre Europa e América Latina (IA/ Unicamp) e Desenvolvimento, Linguagem e Práticas Educativas (FCM/ Unicamp). Lattes: http:// lattes.cnpq.br/4364335240213211. E-mail: tati.fecchio@gmail.com

2. Ver Warburg and Warburgian Traditions of Cultural History in New German Critique de DIERS, Michael; GIRLS, Thomas Girls e MOLTKE, Dorotea publicado em 1995.

3. Para aprofundamento nesta temática ver El arca de No: el mito, la naturaleza y el siglo XVII de Athanasius Kircher e Atilano Martínez Tomé publicada em 1989. Ver também Mitos da Mesopotmia de Henrietta McCall publicada em 1994.

4. Ver Mistrios Nrdicos: Deuses, Runas, Magia, Rituais de Mirella Faur publicado em 2007; Historia da Morte no Ocidente: da Idade Media aos nossos dias de Aries Philippe de 1977 e Lugares dos mortos na cidade dos Vivos: tradies e transformaes fnebres no Rio de Janeiro de Claudia Rodrigues publicado em 1997.

5. O poema relata uma viagem ao país da loucura (Locagonia) realizada por 111 personagens de diferentes classes sociais, cada qual representando um vício humano.

6. This image is in the public domain because its copyright has expired. This applies to the United States, Australia, the European Union and those countries with a copyright term of life of the author plus 70 years.

7. Mechanical reproduction of public domain image. en: Category:Images of paintings en: Category: Paintings of the Louvre Source = Originally from [http://en.wi]

8. Para um estudo da representação do louco como bobo da Corte na Idade Média ver Fools and Folly during the Middle Ages and the Renaissance de Barbara Swain publicado em 1932 e Fools and Jesters at the English Court de John Southworth publicado em 1998.

9. Uma obra que aprofunda a discussão desta obra em relação ao teatro medieval é Gil Vicente e o teatro medieval: a carnavalizao de Iraildes Dantas de Miranda publicado em 
2002.

10. O questionamento da obra de Foucault por Derrida se concentra fundamentalmente nos pressupostos metodológicos e na periodização adotados pelo primeiro na elaboração de Folie et Draison. Histoire de la Folie Ige Classique 1961. Para compreender melhor esta discussão ver PEREIRA NETO, André de Faria. Foucault, Derrida e a História da Loucura: notas sobre uma polêmica de 1998.

11. FOUCAULT, 1972, p.14.

12. FOUCAULT, 1996, p.42-43.

13. O texto foi traduzido em diversas língua e republicado diversas vezes, o que denota sua popularidade e alcance dentro do imaginário de uma época. Jacob Locher adaptou o volume ao Latin em 1497. Em 1500 é realizada por Guyor Marchand uma tradução ao flamengo e nove anos mais tarde Alexander Barclay realiza a tradução ao inglês.

14. Ver Praisers of Folly, Erasmus, Rabelais, Shakespeare de Walter Kaiser publicado em 1964 e Sagesse et folie daprs Erasme de S.Dresden publicado em 1972.

15. FOUCAULT, 1972, p.10.

16. Diz-se que era costume grego colocar uma moeda, chamada bolo, sob a língua do cadáver, para pagar Caronte pela viagem.

17. FOUCAULT,1972, p.10.

18. FOUCAULT, 1972, p.12.

19. FOUCAULT, 1972, p.12.

20. ROSA, 1988, p.32.

21. FOUCAULT, 1996, p.42-43.

22. VIEIRA.

23. ROSA, 1988, p.32.

24. FOUCAULT, 1972. p.29.

25. FOUCAULT, 1972, p.63.

26. HIDALGO,1996, p.26.

27. CARDIN, Fernão In GÂNVALO, 1980.

28. HIDALGO,1996, p.27.

29. HIDALGO,1996, p.18.

30. HIDALGO,1996, p.22.

\section{Referências}

BRANT, Sebastian. The Ship of Fools. Translated by William Gilles with the original woodcuts. London: The Folio Society, 1971.

BURROWES, Patrícia. O Universo segundo Arthur Bispo do Rosrio. Rio de Janeiro: FGV, 1999.

CARDIN, Fernão. Narrativa de Ferno Cardin a 21 de outubro de 1584. 
In GANDAVO.

DIERS, Michael; GIRLS, Thomas; MOLTKE, Dorotea von. Warburg and Warburgian Traditions of Cultural History in New German Critique, no.65. Cultural History/ Cultural Studies, Spring/Summer, 1995.

FAUR, Mirella. Mistrios Nrdicos: Deuses, Ruínas, Magia, Rituais. São Paulo: Pensamento, 2007.

FIGUEIRA, Sérvulo A. Sociedade e Doença Mental. Ed. Campus: Rio de Janeiro, 1978.

FOUCAULT, Michel. A Casa dos Loucos. In Microfísica do Poder. (3.ed.) Trad. Roberto Machado. Rio de Janeiro: Ed. Graal, 1998.

FOUCAULT, Michel. A Historia da Loucura. São Paulo, Perspectiva, 1972.

FOUCAULT, Michel. A Ordem do Discurso - Aula inaugural no Collège de France, pronunciada em 2 de dezembro de 1970. (6.ed.) TradUÇÃO Laura Fraga de Almeida Sampaio. São Paulo: Ed. Loyola, 1996.

FOUCAULT, Michel. Doença mental e psicologia. Tradução de Lílian Rose Shalders. Rio de Janeiro: Tempo Brasileiro, 1975.

FOUCAULT, Michel. Stultífera Navis In História da Loucura na Idade Clássica. (6.ed.) Trad. José Teixeira Coelho Netto. São Paulo: Ed. Perspectiva, 2000.

GOFFMAN, E. Manicômios, Prisões e Conventos, 5ed. Ed.Perspectiva: São Paulo, 1996.

GUIMARÃES ROSA, João. A terceira margem do rio. In: GUIMARÃES ROSA, João. Primeiras estórias. Rio de Janeiro: Nova Fronteira, 1988.

HIDALGO, Luciana. Arthur Bispo do Rosário: o senhor do labirinto. Rio de Janeiro: Rocco, 1996.

JODELET, Denise. Folies et Representacion Sociales. Paris, 1989.

KEISER, Walter. Praisers of Folly, Erasmus, Rabelais, Shakespeare. Londres, 1964

KIRCHER, Athanasius e TOMÉ, Atilano Martínez. El arca de Noé: el mito, la naturaleza y el siglo XVII. Madrid: Colmenar Viejo, 1989.

MCCALL, Henrietta. Mitos da Mesopotâmia. Tradução de Geraldo Costa FiIho. Coleção O Passado Lendário. Editora Moraes, 1994.

MIRANDA, Iraildes Dantas. Gil Vicente e o teatro medieval: a carnavalização em O Auto da Barca do Inferno. 2002. Disponível em http://periodicos.uem. br/ojs/index.php/ActaSciHumanSocSci/article/viewFile/2404/1691 acesso em 2006

PEREIRA NETO, André de Faria. Foucault, Derrida e a Histria da Loucura: notas sobre uma polêmica. Cad. Sade Pblica [online]. 1998, vol.14, n.3, pp. 367-641. ISSN 0102-311X.

Pero de Magalhães. Tratado da terra do Brasil; História da província de 
Santa Cruz, Belo Horizonte: Itatiaia, 1980.

PESSOTTI, Isaias. O Sculo dos Manicmios. Editora 34: São Paulo, 1996.

PHILIPPE, Àries. Histria da Morte no Ocidente: da Idade Média aos nossos dias. Tradução de Priscila Vianna de Siqueira. Rio de Janeiro: F. Alves. 1977.

RODRIGUES, Claudia. Lugares dos mortos na cidade dos Vivos: tradições e transformações fúnebres no Rio de Janeiro. Rio de Janeiro, Secretaria Municipal de cultura, Departamento geral de Documentação e Informação Cultural, Divisão de Editoração, 1997.

ROTTERDAM, Erasmo. Elogio Loucura (Encomium Moriae). Tradução Paulo M. Oliveira. Atena Editora s.d., 2002

S. DRESDEN. Sagesse et folie daprs Erasme, Colloquia Erasmiana Turonensia. Paris-Toronto, 1972.

SOUTHWORTH, John. Fools and Jesters at the English Court. Sutton Thrupp, Gloucestershire, 1998.

SWAIN, Barbara. Fools and Folly during the Middle Ages and the Renaissance. New-York, 1932.

VIEIRA, Alessandor Daros. NOTAS: DER NARRENKAHN OU A CANOA DOS LOUCOS - Uma Análise Literária do Conto "A terceira margem do rio" de João Guimarães Rosa. In REEL - Revista Eletrônica de Estudos. 
Os habitantes da passagem

\section{Tatiana Fecchio da Cunha Gonçalves}

Arte Educadora, Mestre e Doutoranda no Programa de Pós-Graduação em Artes, na Universidade Estadual de Campinas/Unicamp, Instituto de Artes, Arteterapeuta pela Universidade Estadual de Campinas/Unicamp, filiada à AATESP sob inscrição n.058/1105, Coordenadora e docente do curso de Especialização em Arteterapia da Universidade São Marcos, Campus Paulínia e São Paulo, membro do grupo de estudo Desenvolvimento, linguagem e práticas educativas - UNICAMP.

Lattes: http://lattes.cnpq.br/4364335240213211

E-mail: tati_goncalves@uol.com.br; 